\title{
Undergraduate Student Education Programs Regarding Braille Literacy: A Transnational Comparative Study
}

\author{
Vassilios Argyropoulos ${ }^{1}$, Andrea Hathazi ${ }^{2} \&$ Magda Nikolaraizi ${ }^{1}$ \\ ${ }^{1}$ Department of Special Education, University of Thessaly, Volos, Greece \\ ${ }^{2}$ Special Education Department, Faculty of Psychology and Educational Sciences, Babes-Bolyai University, \\ Cluj-Napoca, Romania \\ Correspondence: Vassilios Argyropoulos, University of Thessaly, Department of Special Education, Argonafton \\ \& Filellinon, Volos, Greece. Tel: 30-697-925-6357. E-mail: vassargi@uth.gr
}

Received: August 10, 2019 Accepted: August 23, 2019 Online Published: September 20, 2019

doi:10.5539/hes.v9n4p44 URL: https://doi.org/10.5539/hes.v9n4p44

\begin{abstract}
Developing braille literacy skills represents one of the major goals of the education process for students with vision impairment. Fluency and accuracy in reading and writing facilitate access to information, development of knowledge, active participation, functionality, and independence in social contexts. One of the essential factors that can influence the success in the learning process of the braille code consists of the competences of teachers of students with vision impairment who teach braille. The purpose of this study was to investigate the reflections of 95 undergraduate special education students on their training programs regarding braille in their role as future special education teachers. Data were obtained through questionnaires which were administered in two departments of special education in two European universities. The results reported upon undergraduate students' reflections on their study in braille and confidence in teaching braille to students who are blind. The findings highlighted the need for further training into the braille code in conjunction with its literary and scientific notation.
\end{abstract}

Keywords: braille, students with vision impairment, tertiary education, undergraduate students

\section{Introduction}

Braille code is a tactile code through which individuals with severe vision impairments can read and write and become literate, according to conventional concepts of literacy (Schroeder, 1989; Stephens, 1989). However, recent researches have shown a decrease in the number of people with vision impairments that know to read and write braille. Braille illiteracy has been discussed intensively by many professionals the last decades. According to Wittenstein (1994) and Kleege (2006) in the U.S.A., there has been a nationwide decline in braille literacy. Also, according to Schroeder (cited in Kleege, 2006), braille literacy has declined from 51\% to $9 \%$ during the years 1963-1993. In 2007 from the approximately 57696 legally blind school-age children in the U.S.A., only $10 \%$ were using braille as their primary reading medium (American Printing House for the Blind, 2008). Wormsley (2011) presented that in 2006 in the U.S.A., 64\% of the children who were visually impaired were not reading either print or braille while Australian researchers have lighted the same phenomenon a couple of decades ago (Gale, 2001) that braille literacy has declined significantly and is now at a critically low level worldwide. The National Federation of the Blind (2009) also confirms the same and it seems that this "braille illiteracy" phenomenon has acquired nowadays global qualities (Keil, 2012 in Roe et al., 2014; Penava, Prcić, \& Iličić, 2017; Vernon, 2017).

Many researchers noted the phenomenon of braille illiteracy and tried to provide possible explanations for its existence and evolution. Schroeder (1989), Wittenstein (1994) and Johnston (2004) locate braille illiteracy to the decline in teachers' knowledge in braille. Teachers have been "accused" for incompetence in braille instruction (Eldridge, 1979; Mauer, Pierce (as cited in Wittenstein, 1994); Spungin, 1989; Stephens, 1989). According to Spungin (1989) "Blind children are not being taught braille because the teachers who are supposedly trained to do so themselves do not know the braille codes sufficiently" (p. 42). Spungin (1989) and Mullen (1990) brought forward the inadequate and inconsistent university braille teaching programs as the main cause of teachers' poor braille skills. Additionally, the increase of braille decline may be attributed to the un-orchestrating learning and use of assistive technology such as the increased use of synthetic speech at the expense of braille reading (Amato, 
2002; Argyropoulos, Padeliadu, Avramidis, Tsiakali, \& Nikolaraizi, 2019; Goudiras, Papadopoulos, Koutsoklenis, Papageorgiou \& Stergiou, 2009; Spungin, 1996; Sullivan, 1996). In addition, lack of positive attitudes toward braille and lack of qualified teachers may also be considered as potential indicators of braille decline (Amato, 2009; Mullen, 1991; Spungin, 1989; Willoughby \& Duffy, 1989). Therefore, there has been a debate on how to make braille more attractive and how to motivate teachers - who are supposedly trained to do so - get more involved in teaching braille (Arnold, 2004). In addition, there is an on-going argument about the necessity of learning braille, since there are so many technological advances in the area of assistive technology for people who have vision impairment (Argyropoulos \& Ravenscroft, 2019) which have influenced significantly conventional notions of literacy. These technological advances include multiple and alternate ways of transmitting information in order to address the diverse and unique needs of persons with sensory needs such as deafness or/and blindness (Luckner, Bruce, \& Ferrell, 2016; McKenzie, 2009; Ruppar, Gaffney, \& Dymond, 2015).

Wittenstein (1993) found through his research that teachers whose education emphasized on instructions and/or practice in teaching braille were more likely to hold positive views on teaching braille than those whose education was concentrated on the knowledge of the braille code alone. During 1991-92, Wittenstein (1994) investigated the braille training experiences of 1663 teachers of students who were visually impaired. Based on the results, the majority of the teachers were confident about their skills regarding braille but also stated that more information regarding braille instruction should have been included in their training, putting emphasis on the lack of training regarding the Nemeth code (i. e. is a braille code for encoding mathematical and scientific notation linearly using standard six-dot braille cells for tactile reading by individuals with vision impairment). Wittenstein and Pardee (1996) stated that training teachers only the braille code does not necessarily prepare them to develop literacy skills in their blind students. Teachers whose education involved braille literacy when participated in surveys stated that more direct instructional programs are needed for braille teaching (Argyropoulos, Katsoulis, \& Eliadou, 2007; Johnston, 2004).

From the above, it can be argued that braille decline may stem from a synthesis of mutually dependent factors. These factors may refer to the a. undeveloped range of technological skills that students may have in order to allow them to choose the solution that best meets the demands of literacy tasks (McCall, McLinden, \& Douglas, 2011), b. lack of systematic and up-to-date braille training, c. lack of teachers' motives in learning braille, and d. interpretation of braille as a simple code and not as a medium which has special weight in literacy and communication amongst people with little or no vision or no vision coupled with other sensory disability (such as deafblindness, see Argyropoulos, Nikolaraizi, \& Papazafiri, n.d.). Although the majority of data regarding direct instruction in braille and other literacy skills is pertinent to qualified teachers, the present study is focused on undergraduate students' higher education studies (universities, colleges) regarding braille literacy. As mentioned above, teachers should be appropriately prepared and educated in order to teach braille effectively to their students using all appropriate technological relevant advances. Thus, the authors of this study hold the view that the gravity of the content of braille instruction falls within undergraduate students' theoretical background and practical experience regarding braille literacy. Nevertheless, this kind of braille instruction seems to differ from one organization to another because, as Caton stated (1991), there are no quality standards for teaching braille in colleges and universities and no refresher courses available after graduation take place.

The main aim of the present study is to compare undergraduate students' education programs regarding braille literacy in two European countries (Romania and Greece). This comparison aimed to reveal similarities or/and differences in investigating undergraduate students' voices regarding this training.

\section{The Romanian and Greek Content of Braille Instruction in Tertiary Education}

\subsection{Romanian Context and Content}

In Romania, in order to be a teacher for the visually impaired, you need to get a certificate as special education teacher in accredited university programs and then improve your competences within postgraduate courses, programs, and in-service training programs (Romanian National Education Law no.1/2011). When applying for a teaching job in a school for students with vision impairment, it is needed to provide evidence of braille reading and writing proficiency such as a diploma supplement that proves the completion of the Braille Literacy Teaching course. Teaching braille reading and writing for students with vision impairment can be a component of a more general course on education and rehabilitation of people with vision impairment or can be a separate course that aims to develop practical skills of reading and writing braille. The general objective of the course refers to developing knowledge regarding the characteristics and implications of vision impairment or blindness in reading and writing through large print and braille. The course lasts for 42 hours ( 3 hours per week, meetings 
face to face) and covers thematic areas such as: principles of the braille code, the methodology and stages concerning the development of literacy tactile skills development, implications of reading and writing via braille, strategies and methods used in the education of children with vision impairments, awareness with braille resources such as tactile books, and braille writing devices. In addition, the department offers more than 120 hours practice enabling undergraduate students, who have been registered to the course, to develop practical skills of learning and using contracted and uncontracted braille (i. e. groups of braille letters may be combined into a single braille cell). Finally, tactile awareness regarding braille dots and braille symbols (literary and scientific braille notation), combinations of dots to learn the letters, reading and writing syllables and words and short texts are steps followed during the braille courses in the Romanian system for undergraduate students during their higher education studies.

\subsection{Greek Context and Content}

The main thematic areas of the braille training in Greece regarding the training of undergraduate students who are enrolled at universities are: a. basic information about the nature of tactile perception, and $b$. information and characteristics of the braille code (literary and scientific notation). The course lasts one semester and all lectures are accompanied by workshops with more than 200 hours practice and in the end, all undergraduate students are assessed through a number of tests throughout the semester (on-going assessment) and through final exams at the end of the term (summative assessment). The curriculum which is developed in Greece regarding teaching and learning of braille in teacher education consists of the following strands: theories of literacy acquisition, the braille code (literary and scientific braille notation), the importance of the development pre-braille skills, the teaching of braille (read and write), hand movements in uncontracted braille, spelling, technology for braille users, assessment and selection of appropriate media for reading braille, braille reading schemes, comparisons between print and braille as well as effective practices in teaching literacy through braille.

\subsection{Research Questions}

Thus, the main objective of this study was to investigate undergraduate students' voices regarding their training in braille literacy. More specifically, the present study was designed to provide answers to the following research questions:

1. What were the undergraduate students' reflections on their studies regarding braille?

2. What were the undergraduate students' reflections on their training and readiness in teaching braille?

3. Were any common domains in undergraduate students' needs towards their studies in the braille code?

\subsection{Significance of the Study}

It is important to assess the type of learning, which undergraduate teachers acquire during their studies before they start to teach officially in special schools and/or in integrated settings. First, the process of investigating the content of the preparation in teaching braille has not been the focus of an adequate number of studies with this population. Second, it is important to detect the difficulties the undergraduate students face during their studies in braille literacy. Evidence of this situation would suggest modifications and improvements to the curriculum regarding braille instruction. Third, the comparison of the perspectives of undergraduate students who are prepared in different countries to teach braille will reveal characteristics, which may be categorized at a general level, or at domain-specific level suggesting improvements regarding the content and the process of the corresponding courses in braille literacy. This evidence will be associated with adaptive patterns reconsidering the role of braille not only to schooling but also to culture, societal norms and employment (Spungin, 1996).

\section{Method}

\subsection{Participants}

The participants in this study were 95 undergraduate students (14 males, 81 females) enrolled in higher education courses relevant to special education in two universities (Greece and Romania). In particular, 52 Greek Undergraduate Students (GUSs) $(\mathrm{M}=21.57, \mathrm{SD}=1.089)$ were at their 7 th semester of their studies and 43 Romanian Undergraduate Students (RUSs) $(\mathrm{M}=21.49, \mathrm{SD}=1.183)$ were at their 4th semester of their studies. Their ages ranged from 20 to 26 years and all participants were about to finish their courses on braille.

\subsection{Instrument and Procedure}

The researchers developed a questionnaire with items and questions based on the results and/or on inferences of other relevant research (Eldridge, 1979; Johnston, 1996; Schroeder, 1989; Spungin, 1989; Stephens, 1989; Wittenstein, 1994) which emphasized that the variables which are relevant to the competence of teachers' in teaching braille are pertinent to a. the content of braille, b. teachers' confidence in teaching braille, c. 
conceptualizing braille not only as a code but as a significant part of literacy, d. adequate training in braille, e. mandatory or optional courses (in universities). Hence, the authors developed a 14-item questionnaire (open and closed questions) with input from undergraduate students from both institutions. The questionnaire guide based on the above, consisted of five parts: demographic characteristics, prior knowledge about braille (1 item), reasons for learning braille (1 item), undergraduate students' reflections on their independent study regarding literary braille (7 items) and undergraduate students' reflections on their training and readiness in teaching braille (5 items) (see Appendix).

The final structure and content of the questionnaire was decided by the authors of this study and was translated and adapted into the Greek and Romanian language respectively. The translation involved the two standard procedures of (a) translation and (b) back-translation. In addition, the authors conducted pilot tests and took care to frame the questionnaires in an explanatory manner. The authors from both countries elaborated all variables they wanted to be included in the questionnaire and took into account basic factors for a survey development, such as: clarity, comprehensiveness, acceptability and convenient structure of the questions in order to identify patterns and themes in the participants' responses during the analysis (Rea \& Parker, 2005; Robinson \& Leonard, 2018).

Before the authors administered the questionnaires, they managed to take permission from their institutions for conducting the research, and in turn they followed the ethical principles of the Declaration of Helsinki and obtained signed consent from the undergraduate students using appropriate forms and procedures suggested by the World Medical Association. The authors clarified to all undergraduate students that the questionnaires are anonymous and there are no wrong or right answers. Finally, a cover letter was also included explaining the aim of the study.

\subsection{Data Analysis}

Because of the descriptive nature of the measured variables (for example, reflections on undergraduate students' independent study regarding literary braille) and the absence of latent constructs (a latent construct is a variable that cannot be measured directly), each variable was used descriptively and by itself, rather than reflecting a latent construct. Thus, the researchers - based on other relevant research - captured the variables through questions $(\mathrm{Q})$ or/and items and as a result, information on the internal consistency of items or scales was not relevant because the items that were used literally represented variables. Nevertheless, it may be argued that because the items of the questionnaire were developed based on the results and/or on inferences of other relevant research (see above), the construct validity was secured by minimizing potential threats.

\section{Results}

The results follow the above questionnaire guide regarding the undergraduate students' responses from the two universities. The vast majority of the participants were female (73.1\% Greek and $100 \%$ Romanian) and all of them had done their training in braille code.

Regarding the reasons for learning braille (Q1: What are the reasons which led you to study braille?), 58.3\% of the GUSs stated that they chose to learn braille to differentiate their instruction and therefore facilitate blind people's access to information in school and/or in work environment (the corresponding percentage for the RUSs was $25.6 \%)$. In contrast, the majority of the RUSs $(27.9 \%)$ stated that their choice to learn braille was pertinent to the alternative character that braille bears in communication and another $23.3 \%$ chose to study braille due to curiosity.

The participants' responses regarding their prior knowledge in braille code (Q2: Did you have any background knowledge regarding braille before you decided to take this course?) bore a resemblance. The majority of them did not have any specific knowledge of what braille was $(60 \%$ for the GUSs and $65 \%$ for the RUSs respectively).

The next seven items (closed and open-ended questions) referred to the participants' reflections on their independent study regarding literary braille. When the participants were asked about the duration that was necessary for them to read and write braille (Q3) the majority of the GUSs (57.7\%) needed more than 30 hours but less than 60 hours, whereas the majority of the RUSs $(58.8 \%)$ felt that they needed less than 30 hours. The next question (Q4: What was the most difficult part of learning the literary braille?) revealed another difference between the two groups. Of the GUSs, 59.6\% emphasized the memorization procedure as the hardest one for their independent study, while the responses of the RUSs consisted of a relatively equivalent proportion of statements. In specific, 48.8\% considered the memorization procedure in learning braille as the hardest and $41.9 \%$ considered the procedure of typing braille characters as to be one of the hardest parts of their study regarding 
braille. The fifth item was relevant to the participants' preferred method for their independent study (Q5: What was the best way for you to study literary braille?). Both groups seemed to converge regarding the way which was adopted to study braille. Of the GUSs, $61.5 \%$ and $62.8 \%$ of the RUSs preferred to study braille typing braille characters. The same pattern of agreements was observed within the two groups of the undergraduate students regarding the characters which were easier to learn (Q6: Which characters of the literary braille did you find easier to learn? Can you explain in a few words why is that?). The vast majority of all undergraduate students $(60.5 \%$ of the GUSs and $86.5 \%$ of the RUSs) agreed that the letters they were taught in braille at the beginning of their training were the easiest to learn. However, the explanations between the two groups differed. Specifically, $37.2 \%$ of the RUSs stated it was easy for them to memorize because they consisted of few dot positions. On the contrary, a small percentage of the GUSs $(21.2 \%)$ found some braille characters easy to learn because: a. they consisted of few dots, and b. it was easy to memorize. What is worth mentioning here is the fact the vast majority of the GUSs $(78.8 \%)$ did not give any reasons why they found some braille characters easy to learn, while the corresponding percentage of the RUSs was relatively small $(14 \%)$. The next item aimed at braille characters which the students found the hardest to learn (Q7: Which characters of the literary braille did you find hard to learn? Can you explain in a few words why is that?). Both groups pointed out that paired letters (i.e. contracted types - combinations of two vowels, such as alpha plus iota in the Greek alphabet, the so-called diphthongs) consist of the characters which are hard to learn (51.9\% of the GUSs and 27.9\% of the RUSs). On the other hand, the majority of the RUSs $(30.2 \%)$ detected the difficulty in the letters they studied at the end of their training. Also, it is worth mentioning that $22 \%$ of the GUSs referred to the difficulties they faced when they had to study scientific notation in braille (e.g. mathematics) while there was no such reference by the RUSs. In turn, all students were asked to justify or to make comments on their challenges with braille. $30.8 \%$ of the GUSs mentioned that they were facing difficulties in learning braille characters represented by complex combinations of dot positions, whereas $34.9 \%$ of the RUSs tracked their difficulties in braille characters which are in a mirror-relationship [such as letters R (dot positions: 1235) and W (dot positions: 2456)], and 32.6\% of the same group referred to the braille characters which are presented by many dot positions (such as N, Q, Y, Z). Based on the findings, it can be implied that the combination of many dot positions caused difficulties in the same proportion to the groups from the two countries. Nevertheless, the most striking point was that a significant percentage of the GUSs (55.8\%) and $20.9 \%$ of the RUSs did not give any possible explanations about the challenges they were facing in braille.

In turn, the next item referred to strategies the undergraduate students were using in order to memorize better the braille code (Q8: Did you follow a specific strategy that helped you to memorize better the braille code?). Specifically, the GUSs' responses were categorized mainly into three groups: a. the use of a combination of the dot numbering system and the pattern which the dot positions shaped when representing a letter or a symbol in braille (34.6\%), b. the use of the dot numbering system only (32.7\%), and c. the use of the pattern in which the dot positions shaped when representing a letter or a symbol in braille only (28.8\%). On the other hand, the RUSs' responses seemed to converge to the use of the pattern in which the dot positions formed $(44.2 \%)$ and less of them (27.9\%) were using a combination of the dot numbering system and the pattern which the dot positions revealed to memorize better the braille code. Finally, $27.9 \%$ of the RUSs used to use the numbering system in order to recall the braille code in their independent study.

The last item from the category of the participants' reflections on their independent study regarding literary braille was relevant to the procedure of reading and/or writing braille $(\mathrm{Q} 9$ : What was more difficult for you; to read braille or to write braille? and why is that?). Based on the findings, reading braille was rated as harder for the GUSs $(52.1 \%)$, whereas the majority of the RUSs $(55.8 \%)$ found harder the procedure of writing braille.

The next five items (closed and open-ended questions) refer to the participants' reflections on their readiness regarding literary braille after they had completed the course. The first item of this category referred to the duration of the training in braille (Q10: Do you believe that the duration of one semester is enough for you to learn and practice braille, both literary and scientific?). The majority of the GUSs (53.8\%) and RUSs (60.5\%) felt that one semester was enough for their learning needs. However, the percentages who felt that one semester was not enough and suggested to extend their training in braille for one year were not insignificant ( $46.2 \%$ for the GUSs and $39.5 \%$ for the RUSs respectively). The next question aimed at the participants' readiness in teaching the braille code successfully to children with vision impairment (Q11: How ready do you think you are in order to teach blind children braille?). For this question, all participants rated themselves on a 5-point Likert-type scale from 1 (It is very easy for me to teach braille) to 5 (It is very hard for me to teach braille). An overall estimation revealed that the participants had the impression that they will face few or several difficulties in braille instruction when teaching children with vision impairments $(71.2 \%$ of the GUSs and $74.4 \%$ of the 
RUSs respectively). Also, an independent-samples t-test was conducted to compare the participants' dispositions towards braille teaching. No significant difference were found in rates for the GUSs $(\mathrm{M}=3.12, \mathrm{SD}=0.983)$, and the RUSs $[\mathrm{M}=3.33, \mathrm{SD}=0.969 ; \mathrm{t}(93)=0.52, \mathrm{p}=0.3]$. The magnitude of the differences of the means was very small (eta squared $=0.01$ ).

In turn, next question was germane to the participants' initiative in developing their own instructional methods in teaching braille literacy [Q12: Assuming that you are at the beginning of teaching braille to a blind student, which are the areas that you will first focus on, in order for your student to develop good literacy skills (reading and writing)?]. The highest percentages referred to tactile differentiation (19.2\% of the GUSs and $25.6 \%$ of the RUSs). It seemed that the majority of all participants considered tactile differentiation as an important skill for blind children to develop in order to acquire efficient literacy skills. Additionally, other areas reported by the GUSs as important to focus on were a. cognitive development (17.3\%), b. fine motor skills $(17.3 \%)$, and c. familiarization with a brailler (17.3\%). The areas which were mentioned by the RUSs - apart from tactile differentiation - were a. strategies for memorization (16.3\%), and b. orientation skills in finding pages (11.6\%). Notwithstanding, it is worth mentioning that the percentage of missing responses to this question was relatively high. In specific, $19.2 \%$ of the GUSs and $27.9 \%$ of the RUSs did not answer the question. Relevant to Q12, was Q13 (Q13: Do you believe that children who are blind need to develop some kind of pre-braille skills in order to learn braille?). All participants responded positively to this question and the vast majority of them gave great emphasis on space concepts and tactile sensitivity (86.6\% of the GUSs and $90 \%$ of the RUSs).

Finally, both groups characterized the braille code as a complex system $(\mathrm{Q} 14$ : Since you have completed your training in braille code, how would you characterize it?) at relatively high percentages (47.1\% of the GUSs and $55.8 \%$ of the RUSs). All the above results are depicted in Table 1, highlighting main themes and key-phrases from the participants making it easier for the reader to distinguish convergent and divergent aspects and perspectives from both groups (i.e. GUSs and RUSs).

Table 1. Main themes and key phrases arose from Greek and Romanian Undergraduate Students

\begin{tabular}{llllll}
\hline & \multicolumn{4}{l}{ GUSs } & RUSs \\
\hline Themes & Questions & Key phrases & Key phrases & \\
\hline $\begin{array}{l}\text { Reasons for } \\
\text { studying braille }\end{array}$ & $\begin{array}{l}\text { (reasons) } \\
\text { (reacilitate blind people's access }\end{array}$ & $\begin{array}{l}\bullet \text { alternative } \\
\text { to information }\end{array}$ & $\begin{array}{l}\text { communication } \\
\text { of }\end{array}$ & & \\
& & & $\bullet$ curiosity & &
\end{tabular}

Prior knowledge in braille

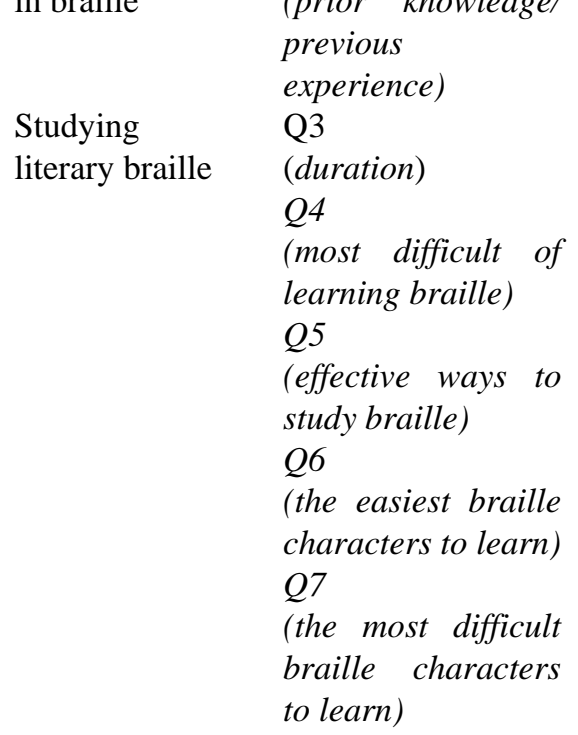

Q8

(memorization strategies)

- did not have any prior

knowledge of the braille code

- $30 \mathrm{hrs}<$ duration $<60 \mathrm{hrs}$

- memorization

- practicing by typing braille characters

- those with the fewest dots

- $\quad$ aired letters (i.e. contracted types - combinations of two vowels)

- scientific notation

- complex combinations of dot positions

- dot numbering system in combination with patterns

- use of dot numbering system

- use of the pattern which is denoted by the dot locations in the
- $\quad$ Duration $<30 \mathrm{hrs}$

- memorization

- typing braille characters

- practicing by typing braille characters

- those with the fewest dots

- braille characters which have a mirror-relationship

- use of the pattern which is denoted by the dot locations in the braille cell

- use of dot numbering system 


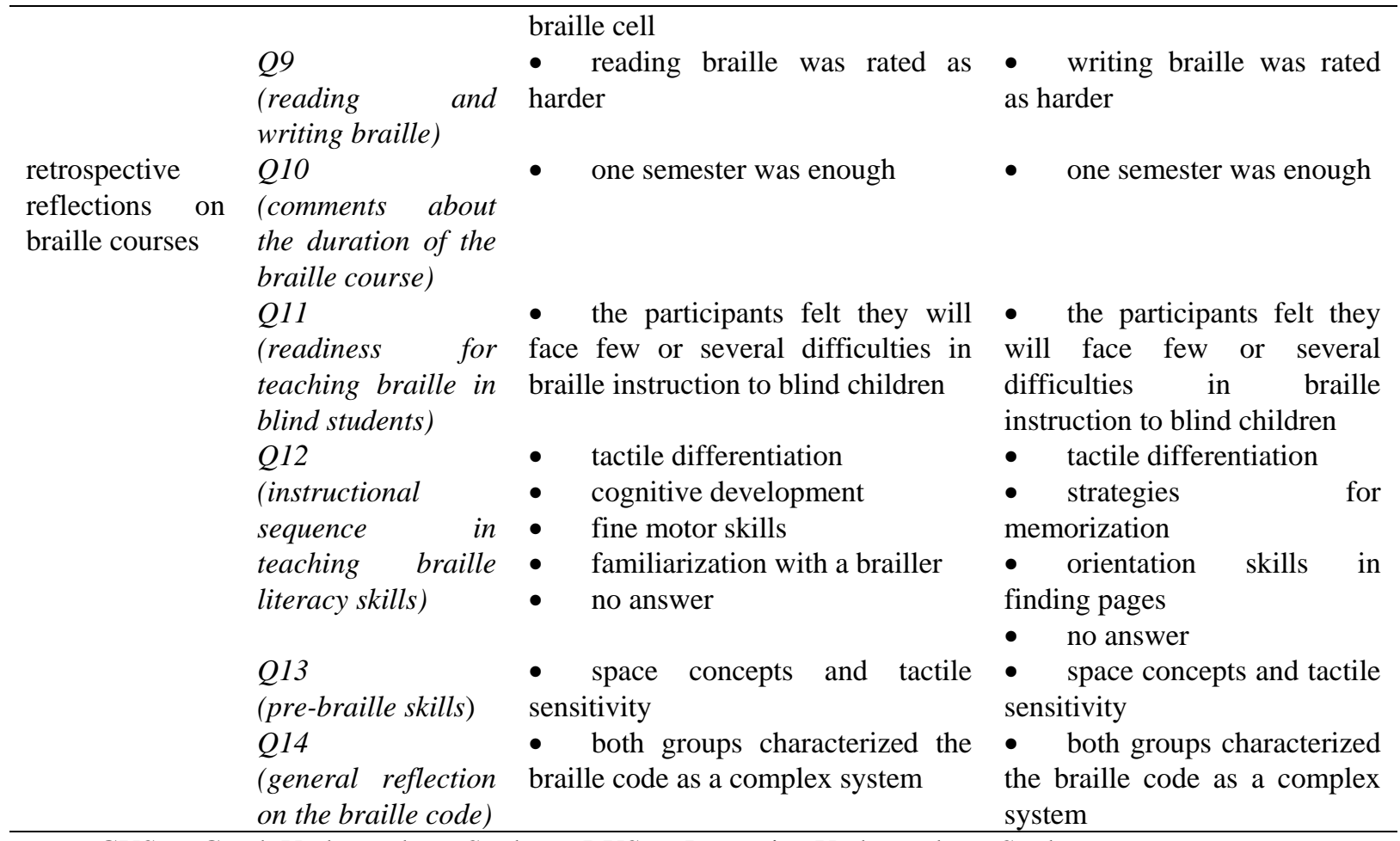

Note. GUSs $=$ Greek Undergraduate Students, RUSs = Romanian Undergraduate Students

\section{Discussion}

The participants' reasons for choosing the braille course were clustered into three strands: differentiation, alternative access to information and curiosity. All these strands are considered fundamental for learning and developing skills.

The findings of the present comparative study (regarding the first research question: undergraduate students' reflections on their study regarding braille) were relevant to strategies applied in studying braille and identification of hard and easy parts of this study. It seemed that the vast majority of all undergraduate students preferred to study braille by typing braille characters, even though $41.9 \%$ of the RUSs considered the procedure of typing braille characters as one of the hardest parts of their study. In contrast, $52.2 \%$ of the GUSs found it hard to read braille. This finding may be justified by the students' impression that 30 hours (or less than 60 hours) are enough to learn the braille code. In fact, reading braille by sighted individuals is not a simple and de facto procedure. It requires sight orientation, recognition of dimensional structure, efficient dot scanning and symmetry detection symmetry (Heller \& Ballesteros, 2006). Thus, the participants, in essence, needed more time to practice braille in order to acquire braille reading skills.

Also, the participants in this study - as all sighted persons - had a holistic approach when reading a text. According to Koenig and Holbrook (2000) that is to say, that sight can "grasp" the whole word or even the whole sentence and make sense of it, while braille - when read by sight - requires more time and energy because it is a one-to-one procedure (one cell every time). According to Chall's stages of reading development (1983), initial reading and decoding are referred to ages 6-7, while confirmation and fluency as well as reading for learning the new are pertinent to ages 7-8 and 9-14 respectively. Hence, it may be argued that even though the majority of the participants felt they mastered the braille code in a relatively short amount of time, nonetheless they started, in essence, to read from the beginning because the reading procedure via braille code was totally different of what they were used to. In addition to this, Swenson (1999) mentioned that "sighted students of all ages are fascinated by braille" (p.155) but there is need for hands-on materials and braille awareness activities to consolidate braille literacy skills.

Finally, the majority of the participants (RUSs and GUSs) stated that they memorize better the braille code when they recall the pattern, which the dot positions form. This finding is in line with relevant research which supports that individuals who are blind read braille by spatial decoding and not by using a numbering system (Heinze, 1986; Millar, 2006). It seems that there are common characteristics between the strategies the sighted 
participants use when recalling the braille code with those which blind students use when they read braille. It may be argued that these spatial structures (either created by sight or by touch) constitute intellectual structures which in turn lead to coherent formations. According to Wadsworth (1989), these structures are called schemata and organize in essence events as they are perceived by the organism and classified into groups, with respect to common characteristics. The second strategy which was adopted by the $32.7 \%$ of the GUSs and the $27.9 \%$ of the RUSs was the numbering system, and it seemed that it brought them some kind of difficulties $(59.6 \%$ of the GUTs and $48.8 \%$ of the RUSs stated that the memorization procedure was the hardest one for their study).

Another point which is worth to mention is the difficulties the GUSs were facing studying the Nemeth code (i. e. Nemeth braille code is an embossed dot system for encoding mathematical and scientific notation linearly using standard six-dot braille cells), whereas the RUSs did not mention it at all. This data may be justified by the limited experience the students had in this short period of their training. Also, it could be argued that literary braille and Nemeth Code have different theoretical underpinnings and for this, it might be confusing to teach them in the same course. DeMario and Lian (2000) suggest the Nemeth Code be taught in a separate course and not along with the literary braille since the Nemeth Code requires more effective instruction because of its scientific and mathematical content.

The findings regarding the second research question (what were the student teachers' reflections on their training and readiness in teaching braille?) were relevant to confidence and readiness. More specifically, it seems that the undergraduate student' confidence was not at high level because a. the vast majority felt they will face difficulties in teaching braille to blind students, b. more than $40 \%$ of the participants felt they needed more training, and c. the vast majority characterized braille code as a complex one which might be true but in conjunction with the previous two statements, it might lead to frustration when the students in questions will graduate and start teaching braille to students with vision impairment. For this, Amato (2002) points out the necessity of refresher braille literacy courses for both new and experienced teachers.

Also, the majority of the participants were aware of the importance of fostering braille literacy to their future blind students by aiming at skills such as tactile differentiation, haptic apprehension, mechanical skills (Olson \& Mangold, 1981) and/or comprehension skills. On the other hand, $19.2 \%$ of the GUSs and 27.9\% of the RUSs did not respond at all to this question. Perhaps these students were from those who felt that they needed more training, or they had questions about the legitimacy of their instructional strategy. Finally, all undergraduate students (approximately $90 \%$ of all participants) strongly supported that for a blind child the presuppositions to learn braille are the development of space concept and tactile sensitivity. These statements are verified from relevant literature which point out that cultivated tactile sensitivity increases the elaboration of the tactile stimuli through active exploration and as a result lead to the development of exploration strategies (Heller, 1984, 1989; Heller \& Myers, 1983; Jones \& Lederman, 2006; Lederman \& Klatzky, 1987, 1996; Millar, 2006).

Finally, the third research question aimed to reveal common patterns in undergraduate students' needs towards their studies in terms of the braille code in both universities. It seems that the undergraduate students' statements from both institutions, although from different countries, highlighted the necessity of more practice and more familiarization with scientific versions of the braille code (such as Nemeth). This may be the case to capture all students' needs including all evidence-based practices in braille literacy (instructions, methodology, skills, use of relevant technology, etc.). Such an interesting work regarding effective practices in teaching literacy through braille has been conducted by McCall, McLinden, and Douglas (2011).

According to the obtained data, an integrated braille training material regarding the teaching of braille may be consisted of three main components: a. the core braille, which may include all the elements of the literary braille, b. the developmental braille (instructions, methodology, techniques, etc.) which may be an adjacent section to the core braille (it is expected that its content will bear many similarities amongst different countries and will depend heavily on research findings), and c. the complementary braille (reasoning and implementations regarding braille contractions).

\section{Conclusions}

Braille knowledge and braille instruction are identified by the Council for Exceptional Children (CEC, 2003) as one of the most important skills required for teachers of students with vision impairment (Pogrund \& Wibbenmeyer, 2008). Keil's findings (2004) showed that teachers for students with vision impairment believed that braille should exist as a course in their training. Johnston (2004) for example, suggested that there is need to reconsider and reform the training needs of teachers who are responsible in teaching braille because they themselves believe to be ill-equipped for this particular task and they strongly believe that there is need for additional training in braille (it was also one of the outcomes of the present study). 
In line with Johnston's perspective, Amato (2002) had suggested to increase the number of semesters where braille is being taught in universities. In 2002, $31 \%$ of the universities that included a course on braille offered braille instruction in only one semester. Amato (2002) presented that according to her respondent's braille should be taught during over two semesters. Nowadays, braille is strongly linked to assistive technological advances and professionals who work with children with vision impairment are required to master braille in conjunction with the use of AT so that they can adequately cover the diverse needs of these children (Ajuwon, Kalene, Griffin-Shirley, \& Okungu, 2016; Alkahtani, 2013; Alquraini \& Gut 2012; Coleman, Cramer, Park, \& Bell, 2015; Papazafiri \& Argyropoulos, 2018).

The main limitation of this study is the small number of participants and the fact that the students who were invited to participate in this study were only from two European countries. Therefore, the results of this research are not generalizable but there is strong evidence that we have reached internationally a threshold regarding the area of teachers' braille training because of: a. the increased braille illiteracy which has been observed in children with vision impairment, and $b$. the increased without appropriate assessment use of assistive technology from students with vision impairment. These comparative studies have the privilege to provide input about common needs and best practices which in turn may lead to a unified suggestion such as the Unified English Braille Code (Jolley, 2006). According to Carey (Chair RNIB, 2016), it seems that the education of students with vision impairment faces an "educational threshold" regarding the braille code and braille literacy skills and underscores its significance by the following:

"the 'war' over coding during the past two decades has absorbed a massive amount of time, energy and, yes, money, when what we need to be focused on is the survival of braille as a viable literary option".

Many debates are arising internationally in the last decade about the braille code and the use of assistive technologies. Some of these debates challenge the effectiveness of the braille code compared to the immense capacities that AT has brought to the fore, whereas other debates focus on the complementarity of AT in the use and enhancement of braille literacy skills. In addition, it has to be mentioned that the braille code has many formats such as literary braille, music braille notation or/and scientific braille notation such as the Nemeth code. Nemeth code (Nemeth, 1972) is a well-known braille system for mathematics and science used in North America as well as in other countries and it seems that teachers need to practice more in braille scientific notations because they contain many combinations of dot patterns compared to the literary braille notation (Asebriy, Raghay, \& Bencharef, 2018; Penava, Prcić, \& Iličić, 2017). Perhaps the answer is in the middle; the role of AT, including augmentative technology, communication technologies, or/and alternative technologies is crucial in order to build up literacy experiences and skills in students with vision impairments and/or with sensory disabilities. An auxiliary technology guide would help undergraduate students as well as professionals to ensure that all features related to technological development are addressed and consequently be able to design and introduce a process appropriate for all students, such as software and devices use, design and implementation of tailor-made equipment adaptations, design and implementation of technology plans and formulation of the appropriate environment to enhance the use of technology (Wong \& Law, 2016). For this, higher education studies relevant to special education, such as braille literacy, has to be coupled with AT opening up broadened concepts of literacy and communication entailing new ways of teaching and instruction (Argyropoulos et al., 2019; Bruce \& Borders, 2015; Edyburn, 2000; Hersh, 2013; McLinden, McCall, Hilton, \& Weston, 2006; Ruppar, Gaffney, \& Dymond, 2015).

\section{References}

Ajuwon, M. P., Kalene, M. M., Griffin-Shirley, N., \& Okungu, A. P. (2016). Reflections of teachers of visually impaired students on their assistive technology competencies. Journal of Visual Impairment \& Blindness, 110, 128-134. https://doi.org/10.1177/0145482X1611000207

Alkahtani, K. D. F. (2013). Teachers' knowledge and use of assistive technology for students with special educational needs. Journal of Studies in Education, 3, 65-86. https://doi.org/10.5296/jse.v3i2.3424

Amato, S. (2002). Standards for Competence in Braille Literacy Skills in Teacher Preparation Programs. Journal of Visual Impairment \& Blindness, 96, 143-153. https://doi.org/10.1177/0145482X0209600303

Amato, S. (2009). Louis Braille Celebration: Challenges and Solutions in Teaching Braille in an Online-Education Model. Journal of Visual Impairment \& Blindness, 103, 78-80. https://doi.org/10.1177/0145482X0910300206

American Printing House for the Blind, (2008). Facts and Figures on Americans with Vision Loss. Retrieved from http://en.wikipedia.org/wiki/Braille 
Argyropoulos, V., \& Katsoulis, F., \& Eliadou, C. (2007). Teachers' and blind students' attitudes towards Braille: A comparative study. Proceedings of the $12^{\text {th }}$ International Council for Education of People with Visual Impairment (ICEVI) World Conference 2005: Achieving Equality in Education: New Challenges and Strategies for Change (pp.1-9). Kuala Lumpur, Malaysia.

Argyropoulos, V., \& Ravenscroft, J. (2019). Assisting People with Vision Impairments through Technology. In: A. Tatnall (Ed.), Encyclopedia of Education and Information Technologies (pp. 1-10). Cham: Springer Nature. https://doi.org/10.1007/978-3-319-60013-0_145-1

Argyropoulos, V., Nikolaraizi, M., \& Papazafiri, M. (in press). Alternative Routes Toward Literacy for Individuals with Deafblindness: The Role of Assistive Technology. In S. Easterbrooks \& H. Dostal, Oxford Handbook of Deaf Studies in Literacy. Oxford: Oxford University Press.

Argyropoulos, V., Padeliadu, S., Avramidis, E., Tsiakali, T., \& Nikolaraizi, M. (2019). An investigation of preferences and choices of students with vision impairments on literacy medium for studying. British Journal of Visual Impairment, 37, 154-168. https://doi.org/10.1177/0264619619838667

Arnold, A. (2004). Learning to read by touch: developing Braille reading schemes. British Journal of Visual Impairment, 22, 89-92. https://doi.org/10.1177/0264619604050044

Asebriy, Z., Raghay, S., \& Bencharef, O. (2018). An Assistive Technology for Braille Users to Support Mathematical Learning: A Semantic Retrieval System. Symmetry, 10, 3-16. https://doi.org/10.3390/sym10110547

Bruce, S. M., \& Borders, C. (2015). Communication and language in learners who are deaf and hard of hearing with disabilities: theories, research, and practice. American Annals of the Deaf, 160, 368-384. https://doi.org/10.1353/aad.2015.0035

Carey, K. (2016). The Survival of Braille is in the Balance. Speech given by Kevin Carey, Chair Royal National Institute of Blind People. International Council on English Braille. Sixth General Assembly RCH1602 v1.0

Caton, H. (1991). Print and braille literacy: selecting appropriate learning media. Louisville, KY: American Printing House of the Blind.

Chall, J. S. (1983). Stages of reading development. New York: McGraw-Hill.

Coleman, M.B., Cramer, E.S., Park, Y., \& Bell, S.M. (2015). Art educators' use of adaptations, assistive technology, and special education supports for students with physical, visual, severe and multiple disabilities. Journal of Developmental and Physical Disabilities, 27, 637-660. https://doi.org/10.1007/s10882-015-9440-6

Council for Exceptional Children. (2003). CEC standards: What every special educator must know (5th ed.). Reston, VA: Author.

DeMario, N. C., \& Lian, M-G. J. (2000). Teachers' perceptions of need for and of newly qualifying teachers during initial training'. British Educational Research Journal, 22, 155-165. https://doi.org/10.1080/0141192960220201

Edyburn, D. L. (2000). Assistive technology and students with mild disabilities. Focus on Exceptional Children, 32, 1-24. https://doi.org/10.17161/fec.v32i9.6776

Eldridge, C. (1979). Braille literacy and higher education. Education of the Visually Handicapped, 11, 8-12.

Gale, G. (2001). In Australia: Braille Literacy Matters. The Educator, 13, 13-20.

Goudiras, D. B., Papadopoulos, K. S., Koutsoklenis, A. CH., Papageorgiou, V. E., \& Stergiou, M. S. (2009). Factors affecting the reading media used by visually impaired adults. British Journal of Visual Impairment, 27, 111-127. https://doi.org/10.1177/0264619609102214

Heinze, T. (1986). Communication skills. In T. Scoll (Ed.), Foundations of Education for Blind and Visually handicapped Children and Youth. Theory and Practice (pp. 301-314). New York: AFB.

Heller, M. A. (1984). Active and Passive Touch: The influence of exploration tome on form recognition. Journal of General Psychology, 110, 243-249. https://doi.org/10.1080/00221309.1984.9709968

Heller, M. A. (1989). Texture perception in sighted and blind observers. Perception and Psychophysics, 45, 49-54. https://doi.org/10.3758/BF03208032

Heller, M. A. (2006). Introduction: Approaches to Touch and Blindness. In M. A. Heller \& S. Ballesteros (Eds.), Touch and Blindness (pp. 1-21). New Jersey: Lawrence Erlbaum Associates. 
https://doi.org/10.4324/9781410615671

Heller, M. A., \& Myers, D. S. (1983). Active and passive tactual recognition of form. Journal of General Psychology, 108, 225-229. https://doi.org/10.1080/00221309.1983.9711496

Hersh, M. A. (2013). Deafblind people, communication, independence and isolation. The Journal of Deaf Studies and Deaf Education, 18, 446-463. https://doi.org/10.1093/deafed/ent022

Johnston, D. (2004). I have mastered the Braille Code but no one has taught me how to teach it, British Journal of Visual Impairment, 22, 17-24. https://doi.org/10.1177/026461960402200104

Jolley, W. (2006). Unified English Braille Code. A literacy bedrock in the digital age. Retrieved from http://www.iceb.org/ICEVI2006_UEB_Paper_Jolley.htm

Jones, L. A., \& Lederman, S. J. (2006). Human hand function. New York: Oxford University Press. https://doi.org/10.1093/acprof:oso/9780195173154.001.0001

Keil, S. (2004). Teaching Braille to children. British Journal of Visual Impairment, 22, 13-16. https://doi.org/10.1177/026461960402200103

Kleege, G. (2006). Visible Braille/Invisible Blindness. Journal of visual culture, 5, 209-218. https://doi.org/10.1177/1470412906066909

Koenig, A. J., \& Holbrook, M. C. (2000). Literacy Skills. In A. J. Koenig \& M. C. Holbrook (Eds.), Foundations of Education. Vol. II. Instructional Strategies for Teaching Children and Youths with Visual Impairments (pp. 264-312). AFB Press.

Lederman, S. J., \& Klatzky, R. L. (1987). Hand movements: A window into haptic object recognition. Cognitive Recognition, 19, 299-302. https://doi.org/10.1016/0010-0285(87)90008-9

Lederman, S. J., \& Klatzky, R. L. (1996). Action for perception: Manual exploratory movements for haptically processing objects and their features. In A. Wing, P. Haggard \& R. Flanagan (Eds.), Hand and brain: Neurophysiology and psychology of hand movements (pp. 431-446). San Diego, CA: Academic Press. https://doi.org/10.1016/B978-012759440-8/50027-X

Luckner, J. L., Bruce, S. M., \& Ferrell, K. A. (2016). A Summary of the communication and literacy evidence-based practices for students who are deaf or hard of hearing, visually impaired, and deafblind. Communication Disorders Quarterly, 37, 225-241. https://doi.org/10.1177/1525740115597507

McCall, S., McLinden, M., \& Douglas, G. (2011). A review of the literature into effective practice in teaching literacy through braille. University of Birmingham / RNIB. Retrieved from http://www.rnib.org.uk/aboutus/research/reports/education/pages/braille_review.aspx

McKenzie, A. R. (2009). Emergent literacy supports for students who are deaf-blind or have visual and multiple impairments: a multiple-case study. Journal of Visual Impairment \& Blindness, 103, 291-302. https://doi.org/10.1177/0145482X0910300507

McLinden, M., McCall, S., Hilton, D., \& Weston, A. (2006). Participation in online problem based learning: insights from postgraduate teachers studying through open and distance education. Distance Education, 27, 331-353. https://doi.org/10.1080/01587910600940422

Millar, S. (2006). Processing Spatial Information from Touch and Movement: Implications from and for Neuroscience. In M. A. Heller \& S. Ballesteros (Eds.), Touch and Blindness (pp. 25-48). New Jersey: Lawrence Erlbaum Associates.

Mullen, E. (1990). Decreased braille literacy: A symptom of a system in need of reassessment. Re: View, 22, 164-167.

National Federation of the Blind (2009). The Braille Literacy Crisis in America, Facing the Truth: A report to the nation. Retrieved from https://nfb.org/images/nfb/documents/word/the_braille_literacy_crisis_in_america.doc

Nemeth, A. (1972). The Nemeth Braille Code for Mathematics and Science Notation, Revision. New York: American Printing House for the Blind.

Olson, M. R., \& Mangold, S. S. (1981). Guidelines and Games for Teaching Efficient Braille Reading. New York: American Foundation for the Blind.

Papazafiri, M., \& Argyropoulos, V. (2018). Assistive technology and special education teachers: The case of students with multiple disabilities and vision impairment. Proceedings of EDULEARN18 (pp. 5485-5492). 
https://doi.org/10.21125/edulearn.2018.1323

Penava, V., Prcić Bilić, A., \& Iličić, L. (2017). The influence of braille literacy programme length on frequency of braille usage. Croatian review of rehabilitation research, 53, 152-162.

Pogrund, R. L., \& Wibbenmeyer, K. A. (2008). Interpreting the Meaning of the Terms Certified and Highly Qualified for Teachers of Students with Visual Impairments. Journal of Visual Impairment and Blindness, 102, 5-15. https://doi.org/10.1177/0145482X0810200102

Rea, L. M., \& Parker, R. A. (2005). Designing and conducting survey research: A comprehensive guide. San Francisco, CA: Jossey-Bass.

Robinson, S. B., \& Leonard, K. F. (2018). Designing Quality Survey Questions ( $1^{\text {st }}$ ed.). LA: SAGE Publications

Roe, J., Rogers, S., Donaldson, M., Gordon, C., \& Meager, N. (2014). Teaching literacy through braille in mainstream settings whilst promoting inclusion: reflections on our practice. International Journal of Disability, Development and Education, 61, 165-177. https://doi.org/10.1080/1034912X.2014.905064

Ruppar, A. L., Gaffney, J. S., \& Dymond, S. K. (2015). Influences on teachers' decisions about literacy for secondary students with severe disabilities. Exceptional Children, 81, 209-226. https://doi.org/10.1177/0014402914551739

Schroeder, F. (1989). Literacy: The Key to Opportunity. Journal of Visual Impairment \& Blindness, 83, 290-93.

Spungin, S. J. (1989). Braille literacy: Issues for blind persons, families, professionals, and producers of braille. New York: American Foundation for the Blind.

Spungin, S. J. (1996). Braille and beyond: Braille literacy in a larger context. Journal of Visual Impairment \& Blindness, 90, 271-274.

Stephens, O. (1989). Braille-Implications for living. Journal of Visual Impairment \& Blindness, 83, 288-289.

Sullivan, E. J. (1996). What the future holds for braille. Retrieved from http://www.duxburysystems. com/hksb96.asp.

Swenson, A. M. (1999). Beginning with Braille. New York, NY: AFB Press.

Vernon, T. (2017). Is Braille relevant in 2017?. Perkins School for the Blind. Retrieved from http://www.perkinselearning.org/transition/blog/braille-relevant-2017

Wadsworth, B. J. (1989). Piaget's theory of cognitive and affective development ( $4^{\text {th }}$ ed.). New York: Longman.

Willoughby, D. M., \& Duffy, S. L. M. (1989). Handbook for itinerant and resource teachers of blind and visually impaired students. Baltimore, MD: National Federation of the Blind.

Wittenstein, S. H. (1993). Braille training and teacher attitudes: Implications for personnel preparation. RE:view, 25, 103-111.

Wittenstein, S. H. (1994). Braille literacy: Preservice training and teachers' attitudes. Journal of Visual Impairment \& Blindness, 88, 516-524.

Wittenstein, S. H., \& Pardee, M. L. (1996). Teachers' voices: Comments on Braille and literacy from the field. Journal of Visual Impairment \& Blindness, 90, 201-209.

Wong, M. E., \& Law, J. S. P. (2016). Practices of Assistive Technology Implementation and Facilitation: Experiences of Teachers of Students with Visual Impairments in Singapore. Journal of Visual Impairment \& Blindness, 110, 195-200. https://doi.org/10.1177/0145482X1611000307

Wormsley, D. P. (2011). A theoretical rationale for using the individualized meaning-centered approach to braille literacy education with Students who have mild to moderate cognitive disabilities. Journal of Visual Impairments \& Blindness, 105, 145-156. https://doi.org/10.1177/0145482X1110500309

\section{Appendix}

Semester: Age

Gender: $\quad$ MALE

$\square$ FEMALE

Q1. What are the reasons which led you to study braille?

Q2. Did you have any background knowledge regarding braille before you decided to take this course? 
$\square$ YES $\square \quad$ NO

If your answer is YES, please write down what did you know about braille, and how did you get this knowledge

Q3. How many hours did it take you to learn braille? (choose one of the following)

$\square$ Less than 30 hours

$\square$ More than 30 hours and less than 60 hours

$\square$ More than 60 hours

Q4. What was the most difficult part of learning the literary braille? ( choose one of the following)

$\square$ Memorization

$\square \quad$ Typing braille characters

$\square \quad$ Something else? (please specify below)

Q5. What was the best way for you to study literary braille? (choose one of the following)

$\square$ Memorization

$\square \quad$ Typing braille characters

$\square \quad$ Something else? (please specify below)

Q6. Which characters of the literary braille did you find easier to learn? Can you explain in a few words why is that?

Q7. Which characters of the literary braille did you find hard to learn? Can you explain in a few words why is that?

Q8. Did you follow a specific strategy that helped you to memorize better the braille code? For example, did you use a strategy which was

$\square \quad$ based on the dot numbering system?

$\square \quad$ based on the pattern which the dot numbering system represents for every symbol (literary or mathematical)?

$\square \quad$ based on the two approaches above?

$\square$ based on another approach? If this is the case, can you provide us some information about this approach?

Q9. What was more difficult for you; to read braille or to write braille? and why is that?

Q10. Do you believe that the duration of one semester is enough for you to learn and practice braille (both literary and scientific)?
$\square$ YES
口 NO

If your answer is NO, how much time do you think is needed to integrate your studies in braille (please write below)

Q11. How ready do you think you are in order to teach blind children braille? (Please choose one of the following)

$\square \quad$ It is very easy for me to teach braille

- It is easy for me to teach braille

- It is neither easy nor hard to teach braille

口 It is hard for me to teach braille

口 It is very hard for me to teach braille

Q12. Assuming that you are in the beginning of teaching braille to a blind student, which are the areas that you will first focus on, in order for the student to develop good literacy skills (reading and writing)? (please provide your answer in a few words)

Q13.Do you believe that children who are blind need to develop some kind of pre-braille skills in order to learn braille?

$\square$ YES

\section{口 NO}

If your answer is YES, please refer to some pre-requisites.

Q14. Since you have completed your training in braille code, how would you characterize it?

$\square \quad$ simple

$\square$ complex

$\square$ sufficient

$\square$ insufficient

口 Other characterization? (give a reason for your answer) 


\section{THANK YOU SO MUCH FOR YOUR COOPERATION}

\section{Copyrights}

Copyright for this article is retained by the author(s), with first publication rights granted to the journal.

This is an open-access article distributed under the terms and conditions of the Creative Commons Attribution license (http://creativecommons.org/licenses/by/4.0/). 